\title{
GERMINAÇÃO DE SEMENTES E VIGOR DE PLÂNTULAS DE Arctium lappa L. SUBMETIDAS À TOXICIDADE DE ALUMÍNIO
}

\author{
SEED GERMINATION AND VIGOR OF Arctium lappa L. SEEDLINGS SUBJECTED TO \\ ALUMINIUM TOXICITY \&
}

GERMINACIÓN DE SEMILLAS Y VIGOR DE PLÁNTULAS DE Articum lappa L. SOMETIDAS A TOXICIDAD POR ALUMINIO \&

Recebido em: 25/11/2020 - Aprovado em: 04/02/2021 - Publicado em: 26/07/2021

\section{http://dx.doi.org/10.18011/bioeng2020v15n1p154-167}

\begin{abstract}
Juliana Milene Silverio ${ }^{1}$ (juliana.milene@hotmail.com)
Cleberton Correia Santos ${ }^{1}$ (cleber_frs@yahoo.com.br)

Rodrigo da Silva Bernardes ${ }^{1}$ (rodrigo.bernardes95@hotmail.com)

Giselly Marques Espíndola ${ }^{1}$ (gisellymarquesespindola@hotmail.com)

Hércules Lazari Meurer ${ }^{1}$ (herculesmeurer@outlook.com)

Maria do Carmo Vieira' (mariavieira@ufgd.edu.br)
\end{abstract}

1 Universidade Federal da Grande Dourados (UFGD). Dourados, MS, Brasil.

\section{RESUMO}

O alumínio (Al) presente nos solos ácidos reduz o potencial fisiológico de sementes e limita o crescimento plântulas de diversas espécies de interesse agronômico e medicinal. Entretanto, informações quanto à toxicidade do Al em Arctium lappa L. (bardana, Asteraceae) são escassas. Objetivou-se nesse estudo avaliar o efeito do estresse por alumínio na germinação e no vigor de plântulas de $A$. lappa. Foram testadas cinco concentrações de sulfato de alumínio hidratado $\mathrm{Al}_{2}\left(\mathrm{SO}_{4}\right)_{3} \cdot 16 \mathrm{H}_{2} \mathrm{O}: 0$ (controle), 5, 10, 15 e $20 \mathrm{mmol} \mathrm{L}$ 1. O teste de germinação foi feito em caixas do tipo Gerbox (sobre papel - SP) e em rolo papel - RP, utilizando papel germitest ${ }^{\circledR}$ umedecidos 2,5 vezes seu peso seco. As sementes foram mantidas em câmaras de B.O.D, sob $20-30^{\circ} \mathrm{C}$ e luz branca constante. O potencial fisiológico das sementes e vigor de plântulas foi avaliado por meio dos testes de primeira contagem de germinação (4 dias), germinação (7 dias) e comprimento de plântulas. Observamos redução da germinação conforme aumento da concentração de $\mathrm{Al}$ em substrato SP. Os menores comprimentos da parte aérea das plântulas ocorreram com $20 \mathrm{mmol} \mathrm{L}^{-1}$ de Al e no substrato SP. Ocorreu inibição radicular das plântulas conforme aumento da concentração de Al nos dois substratos, especialmente no SP. O estresse por alumínio e substrato SP afetou negativamente a germinação de sementes e vigor das plântulas de A. lappa.

Palavras-chave: Bardana. Estresse. Planta medicinal. Potencial fisiológico.

Artigo publicado sob a licença Creative Commons - Atribuição 4.0 Internacional (CC BY 4.0). 


\section{INTRODUÇÃO}

A germinação de sementes é, em muitas espécies, o primeiro estágio da propagação, sendo que as condições ambientais podem afetar o estabelecimento da planta no habitat em que está inserida (KOSZO et al., 2007).

Em regiões de clima tropical e subtropical, os solos possuem altos graus de intemperismo e elevados teores de argila oxídica e hidróxidos de ferro e alumínio (Al) (VENDRAME et al., 2010; RABEL et al., 2018). Em função do avançado grau de intemperismo os solos apresentam baixas cargas estruturais e baixa fertilidade (WEBER et al., 2005; SOUZA et al., 2015).

No Cerrado brasileiro, um bioma de elevada variabilidade ecológica, o $\mathrm{pH}$ do solo varia ente 4,0-5,5, limitando a disponibilidade de nutrientes às plantas (HARIDASAN, 2008; LIMA et al., 2010). Nessa perspectiva, a toxicidade por Al afeta negativamente os processos germinativos e o desenvolvimento das plantas.

No Brasil, cerca de $60 \%$ das áreas agricultáveis possuem problemas com altos teores de Al no solo (MACHADO et al., 2015). Algumas espécies são tolerantes e outras sensíveis ao Al. Geralmente as espécies sensíveis a toxicidade ao Al apresentam diminuição no alongamento radicular e dos caracteres metabólicos e de crescimento da parte aérea (HARTWIG et al., 2007).

$\mathrm{Na}$ germinação de sementes, a exposição ao Al aumenta a permeabilidade da membrana celular, ocasionando a perda dos solutos do interior das sementes, podendo causar peroxidação lipídica (SIMONOVICOVÁ et al., 2004; GORDIN et al., 2013), reduzindo o potencial fisiológico e germinativo das sementes.

$\mathrm{Na}$ literatura existem alguns trabalhos descrevendo o efeito do $\mathrm{Al}$ nos processos germinativos. Machado et al. (2015), ao avaliarem a germinação de sementes de Jatropha curcas L. expostas a cinco concentrações de Al, encontraram que o elemento diminuiu em até $90 \%$ a germinação, além de reduzir 76 e $83 \%$ do comprimento e matéria seca das raízes das plântulas, respectivamente.

Além disso, fatores como o substrato podem afetar o potencial de germinação das sementes, uma vez que há diferença no contato com a semente na fase de protrusão radicular, tornando-se necessário conhecer o substrato adequado para diversas espécies cujas informações são escassas. 
A bardana (Arctium lappa L.), é uma espécie da família Asteraceae, originária da Europa e da Sibéria. Com valor alimentício e medicinal chegou ao Brasil por meio dos imigrantes japoneses (MORGAN, 2003). A planta adaptou-se muito bem às condições do Brasil, e pode ser encontrada no sul e sudeste do país (FRANCO et al., 2019).

Com alto potencial nutricional, a espécie possui em sua constituição aminoácidos essenciais (ácido aspártico e arginina), vitaminas e minerais, especialmente nas raízes (CHAN, 2011). Na medicina popular, as folhas e raízes podem ser utilizadas no controle de cólicas, gripe, artrite e insuficiência cardíaca. As sementes são indicadas como diurética, tosse seca, resfriados e irritação da garganta (MORGA, 2003; MUNARIN et al., 2010). A espécie também possui atividade anticancerígena (MING et al., 2004) e antioxidante (LIMA et al., 2006; FRANCO et al., 2019).

Por não haver registro de informações e com intuito de verificar se A. lappa é sensível ou tolerante a toxicidade do Al e estabelecer o melhor substrato para essa espécie, objetivou-se com este trabalho avaliar o potencial germinativo e vigor de plântulas de $A$. lappa submetidas ao estresse por alumínio em diferentes substratos.

\section{MATERIAIS E MÉTODOS}

O ensaio foi realizado no Laboratório de Tecnologia de Sementes, na Faculdade de Ciências Agrárias, da Universidade Federal da Grande Dourados (UFGD), Dourados - Mato Grosso do Sul, Brasil. Frutos de A. lappa foram coletados de plantas matrizes localizadas

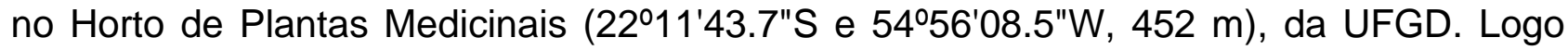
após, realizou-se o beneficiamento manual, e as sementes foram imersas em solução de hipoclorito de sódio (2\%), por 5 minutos, para desinfestação. A espécie foi identificada e uma exsicata está depositada no Herbário, da UFGD, sob no 4713.

As sementes foram submetidas ao estresse utilizando sulfato de alumínio hidratado $\mathrm{Al}_{2}\left(\mathrm{SO}_{4}\right)_{3} \cdot 16 \mathrm{H}_{2} \mathrm{O}$ nas concentrações de 0 (controle), 5, 10, 15 e $20 \mathrm{mmol} \mathrm{L}^{-1}$. Os testes foram realizados em caixas do tipo Gerbox (sobre papel) e em rolo papel, utilizando papel germitest ${ }^{\circledR}$ umedecidos 2,5 vezes seu peso seco utilizando a solução com a concentração correspondente. No substrato rolo papel, as sementes foram dispostas na linha do terço superior do papel. 
O delineamento experimental utilizado foi o inteiramente casualizado, em que os tratamentos foram arranjados em esquema fatorial $5 \times 2$, com quatro repetições de 50 sementes. As sementes foram mantidas em câmaras de B.O.D (Biochemical Oxygen Demand), sob $20-30^{\circ} \mathrm{C}$, luz branca constante e fotoperíodo de $12 \mathrm{~h}$ luz/12 $\mathrm{h}$ escuro.

O potencial fisiológico das sementes e vigor de plântulas foi avaliado por meio dos seguintes testes:

Primeira contagem e teste de germinação: a avaliação da primeira contagem foi feita aos 4 dias após a semeadura, baseando-se em resultados de pré-testes. $O$ teste de germinação foi realizado aos 7 dias, no qual utilizaram-se quatro repetições de 50 sementes, as quais foram colocadas para germinar em caixas plásticas do tipo "Gerbox" sobre duas folhas de papel-toalha ("germitest") sobre papel - SP e rolo papel (RP), umedecidas com volume de água destilada correspondente a 2,5 vezes o seu peso seco. A germinação foi calculada considerando as plântulas com protrusão e emissão radicular $\geq$ 2,0 mm e emissão de hipocótilo (BRASIL, 2009) com os resultados expressos em porcentagem (\%).

Comprimento de plântulas: aleatoriamente dez plântulas foram separadas para medir o comprimento da raiz primária e da parte aérea (distância do coleto até inflexão da folha mais alta) das plântulas normais com auxílio de uma régua graduada em milímetros. Os resultados médios foram expressos em $\mathrm{cm}$ plântula ${ }^{-1}$.

Os dados de germinação foram transformados em arcoseno da raiz quadrada de $x$ $+0,5$ para normalização, e quando significativos foram apresentados os valores reais. Os dados foram submetidos à análise de variância (ANOVA) e quando significativos (teste $F$, $p<0,05$ ), as médias foram comparadas pelo teste t de Bonferroni para substratos $(p<$ $0,05)$, e à análise de regressão para concentrações de alumínio, testando o modelo linear e quadrático $(p<0,05)$, utilizando o software SISVAR.

\section{RESULTADOS E DISCUSSÃO}

Em geral, a germinação de sementes e o vigor das plântulas de $A$. lappa foi afetado pela concentração de alumínio. Até os sete dias após a semeadura, realizamos a caracterização visual do processo de germinação, desde a protrusão radicular até a formação da plântula normal (Figura 1). 
Figura 1 - Caracterização da germinação e formação de plântula normal de Arctium lappa L. Tg= semente com tegumento; $\mathrm{PR}=$ protrusão radicular; $\mathrm{ER}=$ emissão da radícula; $\mathrm{RP}=$ raiz principal; $\mathrm{Co}=$ coleto; $\mathrm{H}=$ hipocótilo; $\mathrm{Ga}=$ gema apical; $\mathrm{Fg}=$ folha gêmula; $\mathrm{PN}=$ plântula normal.

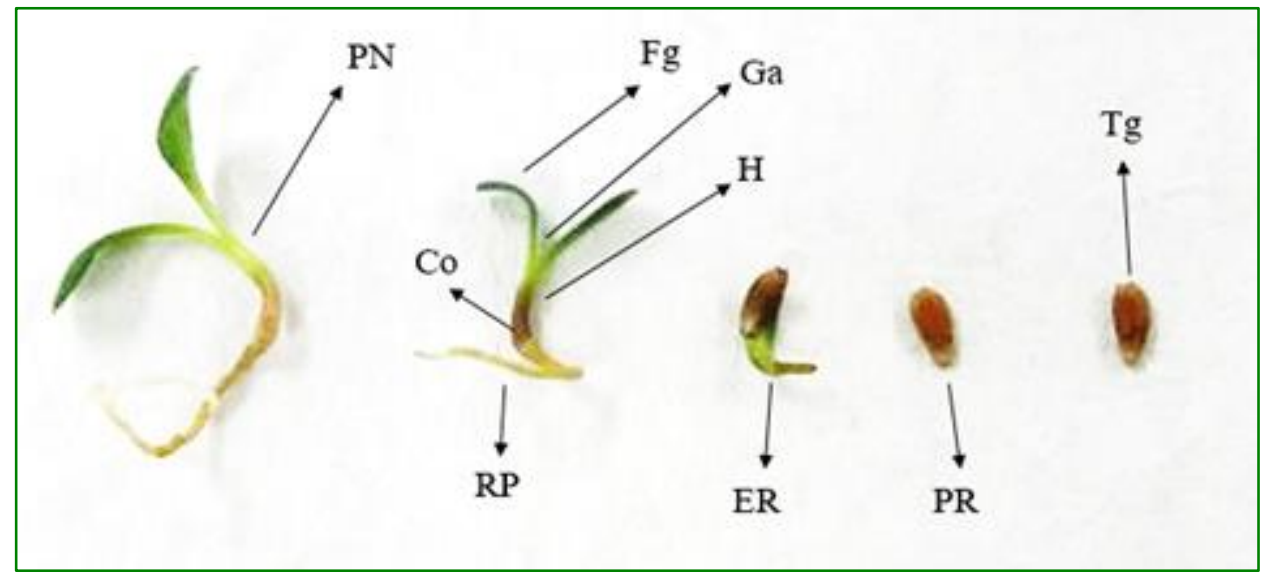

Fonte: elaboração dos autores (2018).

Constatamos interação entre as concentrações de alumínio e substratos testados sobre a primeira contagem de germinação - PCG (Figura 2) e para a germinação de sementes de $A$. lappa (Figura 3). Na PCG, os dados em rolo papel não foram significativos ( $p>0,05$ ), apresentando média geral de $90 \%$, enquanto sobre papel houve ajuste quadrático, sendo o maior e menor valor foi de $100 \%$ e $68 \%$, sem a presença $\left(0 \mathrm{mmol} \mathrm{L}^{-1}\right)$ e com $13 \mathrm{mmol} \mathrm{L}^{-1}$ de $\mathrm{Al}$, respetivamente (Figura 2). No que se refere à germinação de sementes, observamos redução dos valores conforme aumento da concentração de Al em substrato SP, com valor de 94\% (Figura 3). Por outro lado, em rolo papel não houve efeito significativo da concentração de alumínio, apresentando média geral de 95,8\%. 
Figura 2 - Primeira contagem de germinação [PCG (\%)] de sementes de Arctium lappa L. submetidas ao estresse por alumínio em diferentes substratos $(\mathrm{RP}=$ rolo papel; $\mathrm{SP}=$ sobre papel $)$ em condições de laboratório. * parâmetro da equação polinomial $(p<0,05)$

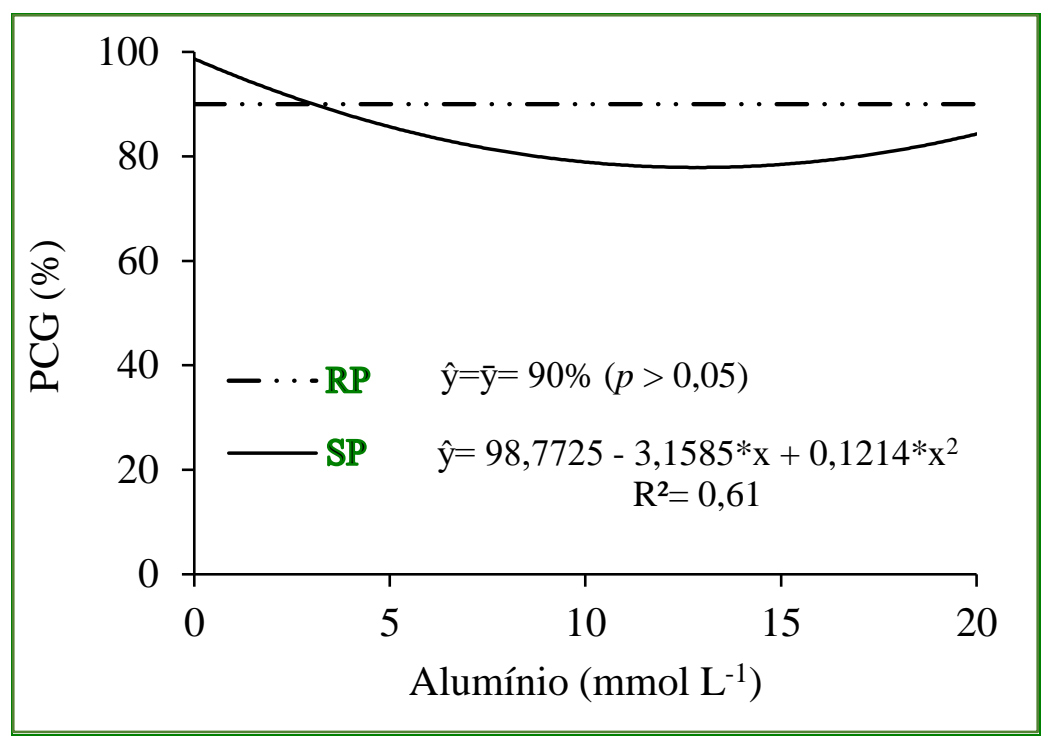

Fonte: elaboração dos autores (2018).

A exposição das sementes ao Al aumenta a permeabilidade da membrana celular, ocasionando maior efluxo dos solutos do interior das sementes, e consequentemente peroxidação lipídica e degradação de proteínas (SIMONOVICOVÁ et al., 2004; MERIÑOGERGICHEVICH et al., 2010; GORDIN et al., 2013), resultando em menor potencial fisiológico e bioquímico das sementes, reduzindo os indicadores germinativos. Similar aos resultados do nosso estudo com $A$. lappa, Samad et al. (2017) verificaram redução da germinação de Cicer aeriatinum L. e Oryza sativa L. quando submetidas ao estresse por Al.

Todavia, embora o Al tenha reduzido a germinação da $A$. lappa, seu efeito de toxicidade não foi tão pronunciado sobre essa característica, uma vez que os valores foram $>90 \%$ em RP, demonstrando que a espécie apresenta pouca sensibilidade no que se refere à protrusão radicular e emissão do hipocótilo nessas condições. 
Figura 3 - Percentagem de germinação de sementes de Arctium lappa L. submetidas ao estresse por alumínio em diferentes substratos $(\mathrm{RP}=$ rolo papel; $\mathrm{SP}=$ sobre papel) em condições de laboratório. * parâmetro da equação linear $(p<0,05)$

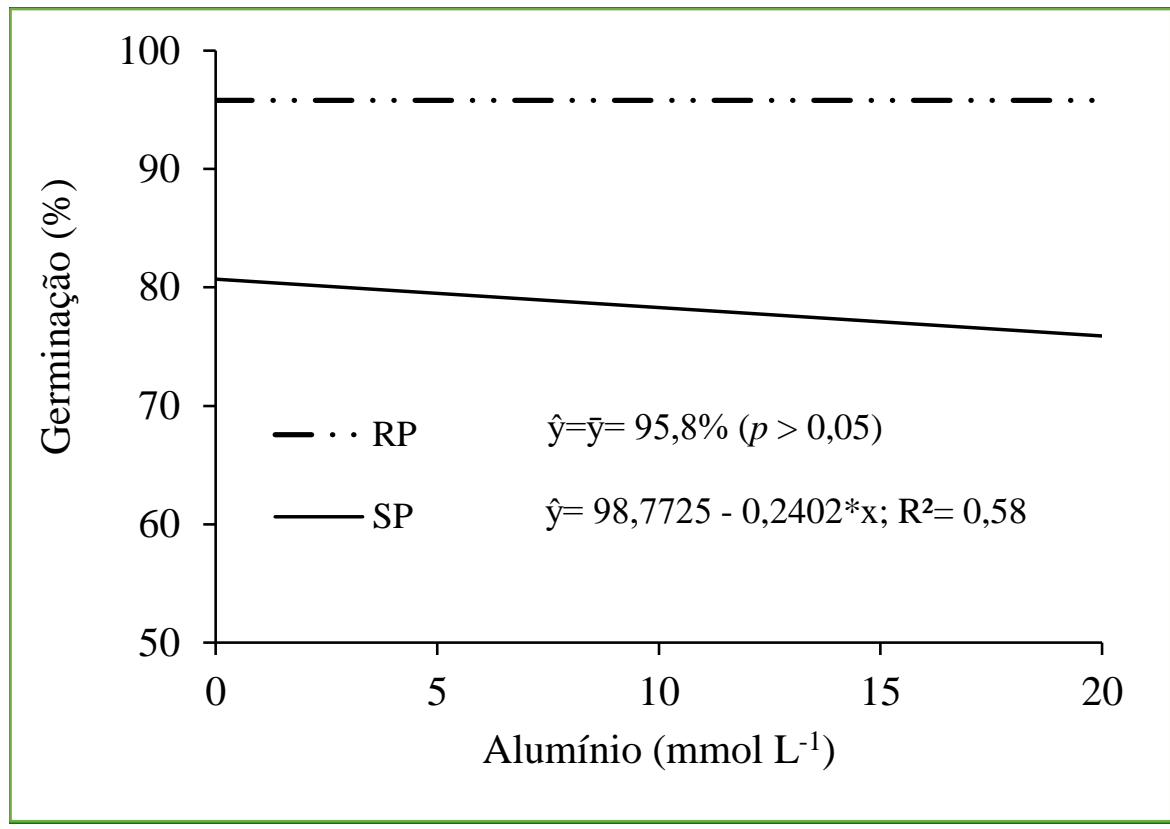

Fonte: elaboração dos autores (2018).

O comprimento da parte aérea (CPA) foi influenciado pelos fatores em estudo isoladamente, sendo que os menores valores (1,00 e 1,10 cm/plântula) ocorreram nas plântulas sob $20 \mathrm{mmol} \mathrm{L}^{-1}$ de Al (Figura 4a) e em substrato SP, respectivamente (Figura 4b). O Al em concentrações acima do tolerável para cada espécie, ocasiona o estresse oxidativo e reduz os processos metabólicos (ZHANG et al., 2010; SILVA; MATOS; 2016), limitando os aspectos de crescimento. De maneira semelhante, plântulas de Jatropha curcas L. submetidas ao estresse por Al tiveram menor comprimento da parte aérea (MACHADO et al., 2015). Em geral, quanto ao substrato, os maiores valores de PCG, germinação e CPA em RP deve-se ao fato de haver melhores condições para expansão da parte aérea e manutenção da umidade no substrato, uma vez que as sementes são envoltas pelo papel germitest ${ }^{\circledR}$. 
Figura 4 - Comprimento da parte aérea (CPA) de plântulas de Arctium lappa L. submetidas ao estresse por alumínio (a) e diferentes substratos $(\mathrm{RP}=$ rolo papel; $\mathrm{SP}=$ sobre papel) $(\mathrm{b})$ em condições de laboratório. * parâmetro da equação linear e teste t de Bonferroni $(p<0,05)$

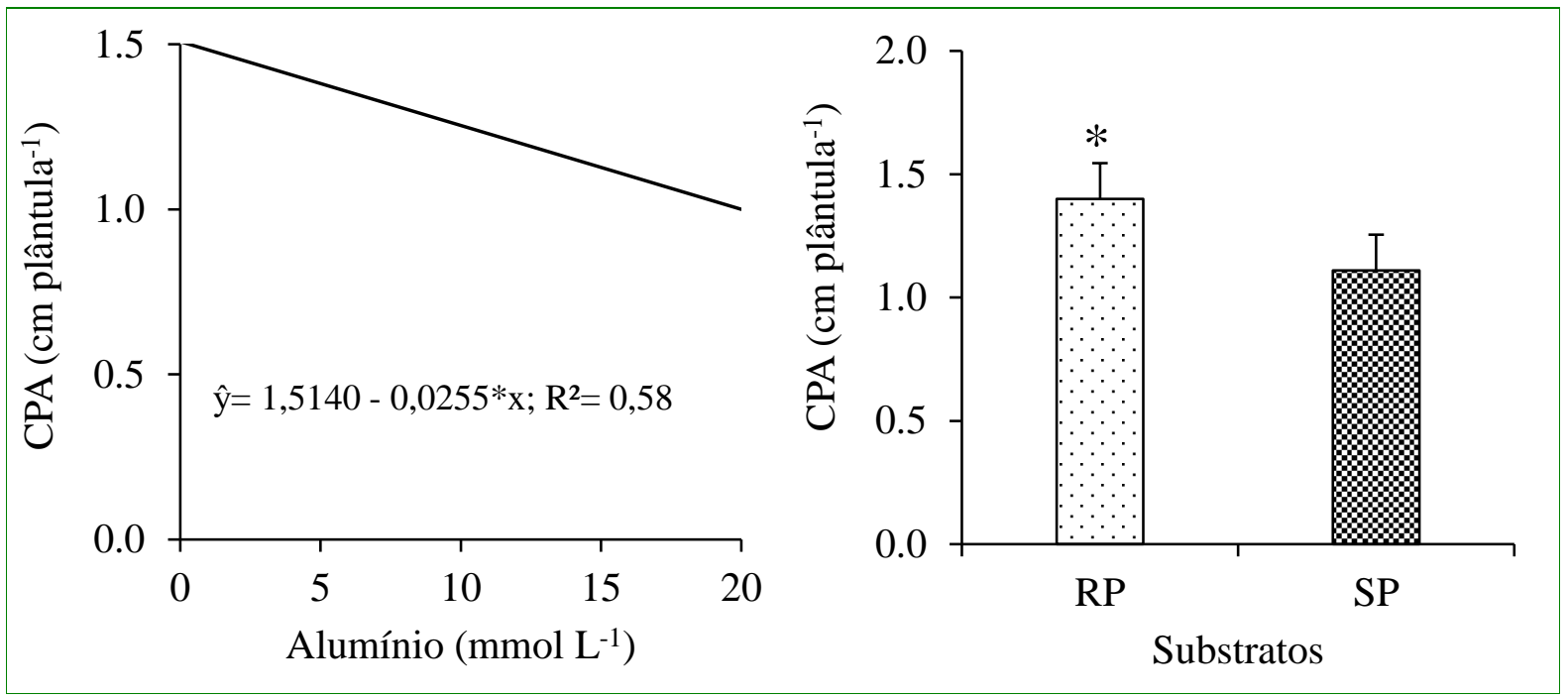

Fonte: elaboração dos autores (2018).

Verificamos interação entre as concentrações de $\mathrm{Al}$ e os substratos para o comprimento da raiz (CR), sendo que nos dois substratos houve efeito linear decrescente conforme aumento das concentrações de Al, sendo que os menores CR foram de 0,20 e $0,55 \mathrm{~cm}$ em substrato sobre papel e rolo papel com $20 \mathrm{mmol} \mathrm{L}^{-1}$ de $\mathrm{Al}$, respectivamente (Figura 5). Uma das primeiras respostas visuais nas plantas quanto à toxicidade do Al é inibição radicular (DEGENHARDT et al., 1998; ECHAR; CAVALLI-MOLINA, 2011), tal como observado na $A$. lappa. O Al reduz elasticidade celular em função do menor afrouxamento nas paredes celular devido às reações desse elemento com as cadeias de ácido poligalacturônico e cargas de polissacarídeos (ZHENG et al., 2004; YANG et al., 2011; MOTA et al., 2020).

$\mathrm{Na}$ literatura outras espécies também tiveram inibição do crescimento radicular em resposta à toxicidade do Al, como em Phaseolus vulgaris L. (DOMINGUES et al., 2013), Trifolium pratense L. (SCHEFFER-BASSO; PRIOR, 2015), Helianthus annuus L. (LI et al., 2015) e Lactuca sativa L. (SILVA; MATOS, 2016). 
Figura 5 - Comprimento de raiz de plântulas de Arctium lappa L. submetidas ao estresse por alumínio em diferentes substratos $(\mathrm{RP}=$ rolo papel; $\mathrm{SP}=$ sobre papel). * parâmetro da equação linear $(p<$ $0,05)$

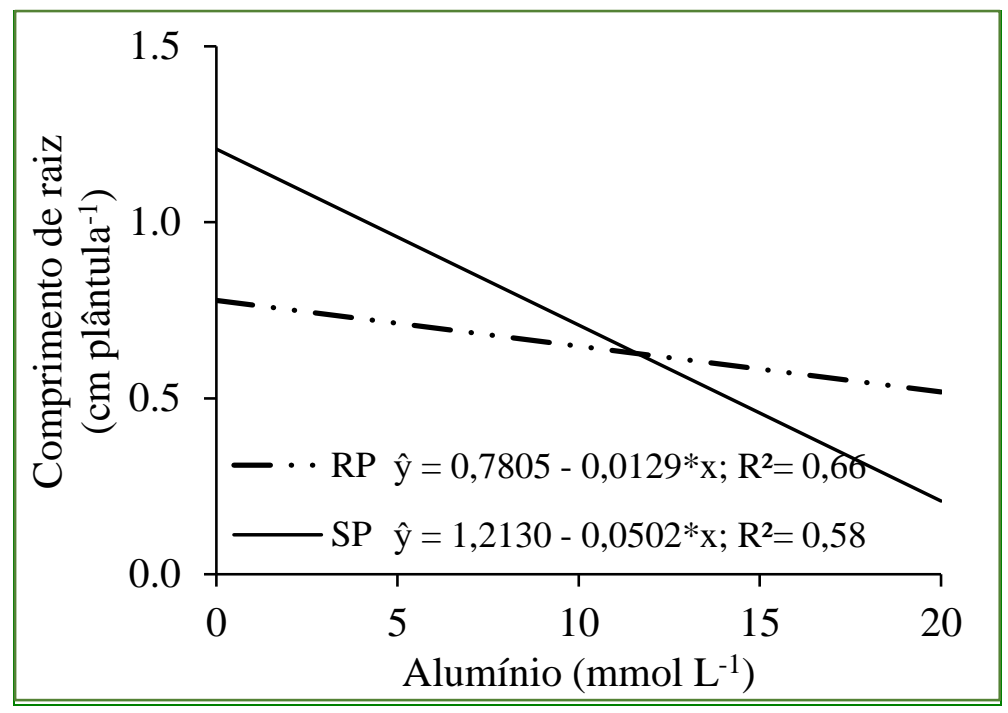

Sementes de A. lappa expostas as concentrações de Al formaram plântulas com aspectos morfológicos reduzidos de maneira acentuada a partir de $10 \mathrm{mmol} \mathrm{L}^{-1}$, sendo que plântulas do tratamento controle tiveram as folhas gêmulas expandidas em comparação aos demais tratamentos (Figura 6). Ressaltamos que quanto mais rápido as plântulas apresentarem folhas expandidas maior será a interceptação luminosa, maximizando os processos fisiológicos e a produção de fotoassimilados.

Figura 6 - Aspecto visual de plântulas de Arctium lappa L. submetidas ao estresse por alumínio. ( $\mathrm{a}=$ 0 - controle; $b=5 ; c=10 ; d=15 ; e=20 \mathrm{mmol} \mathrm{L}^{-1}$ de Al).

\begin{tabular}{|r|r|r|r|r|r|r|r|}
\hline (a) & (b) & (c) & & (d) & (e) \\
\hline & & & & & \multicolumn{2}{|c|}{} & \\
\hline
\end{tabular}

Fonte: Elaboração dos autores (2018) 
Em perspectivas futuras, estudos em casas de vegetação e condições de campo devem ser realizados a fim de estabelecer informações fitotécnicas para o cultivo de $A$. lappa em resposta ao uso de corretivos em solos ácidos, tal como nas regiões tropicais.

\section{CONCLUSÕES}

O estresse por alumínio afetou negativamente a germinação de sementes e o vigor das plântulas de Arctium lappa L. O substrato rolo papel contribuiu em melhores indicadores de germinação e comprimento das plântulas da espécie.

\section{REFERÊNCIAS}

BRASIL. Ministério da Agricultura, Pecuária e Abastecimento. Regras para Análise de Sementes. Secretaria de Defesa Agropecuária. Brasília: MAPA/ACS5 2009. 395 p.

CHAN, Y. S.; CHENG, L. N.; WU, J. H.; CHAN, E.; KWAN, Y. W.; LEE, S. M.; LEUNG, G. P.; YU, P. H.; CHAN, S.W. A review of the pharmacological effects of Arctium lappa (burdock). Inflammopharmacology, v. 19, n. 5, p. 245-54, 2011.

DEGENHARDT, J.; LARSEN, P. B.; HOWELL, S. H.; KOCHIAN, L. V. Aluminum resistance in the Arabidopsis mutant alr-104 is caused by an aluminum-induced increase in rhizosphere pH. Plant Physiology, v. 117, n. 1, p. 19-27, 1998.

DOMINGUES, A. M.; SILVA, E.; FREITAS, G.; GANANÇA, J. F.; NÓBREGA, H.; SLASKI, J. J.; CARVALHO, M. A. P. Aluminium tolerance in bean traditional cultivars from Madeira. Revista de Ciências Agrárias, v. 36, n. 2, p. 148-156, 2013.

ECHART, C. L.; CAVALLI-MOLINA, S. C. Fitotoxicidade do alumínio: efeitos, mecanismo de tolerância e seu controle genético. Ciência Rural, v. 31, n. 3. p. 531-541, 2001.

FRANCO, F. B.; SILVA, T. T. da; BASTOS, R. G.; SANTOS, G. B. Triagem fitoquímica e atividade antioxidante de Arctium lappa Linne e Myrcianthes pungens. Revista Científica da UNIFENAS, v. 1, n. 1, p. 12-21, 2019.

GORDIN, C. R. B.; MARQUES, R. F.; ROSA, R. J. M.; SANTOS, A. M.; SCALON, S. P. Q. Emergência de plântulas e crescimento do pinhão manso exposto a alumínio. Semina:

Ciências Agrárias, v. 34, n. 1, p. 147-156, 2013.

HARIDASAN, M. Nutritional adaptations of native plants of the Cerrado biome in acid soils. Brazilian Journal of Plant Physiology, v. 20, n. 3, p. 183-195, 2008. 
HARTWIG, I.; OLIVEIRA, A. C.; CARVALHO, F. I. F.; BERTAN, I.; SILVA, J. A. G.; SCHMIDT, D. A. M.; VALÉRIO, I. P.; MAIA, L. C.; FONSECA, D. A. R.; REIS, C. E. S. Mecanismos associados à tolerância ao alumínio em plantas. Semina: Ciências Agrárias, v. 28, n. 2, p. 219-228, 2007.

KOSZO, C. R. R; RINALDI, M. C. S.; BARBEDO, C. J. Germinação de sementes de Erythrina speciosa Andr., Eugenia brasiliensis Lam. e Cucumis sativus L. em meio ácido. Hoehnea, v. 34, n. 3, p. 271-282, 2007.

LI, M.; QIN, R.; JIANG, W.; LIU, D. Cytogenetical effects of aluminum on root meristem cells of Helianthus annuus L. Botanical Science, v. 93, n. 1, p. 15-22, 2015.

LIMA, A. R.; BARBOSA, V. C.; SNTOS FILHO, P. R.; GOUVÊA, C. M. C. P. Avaliação in vitro da atividade antioxidante do extrato hidroalcoólico de folhas de bardana. Revista Brasileira de Farmacognosia, v. 16 n. 4, p. 531-536, 2006.

LIMA, C. G. R.; CARVALHO, M. P.; NARIMATSU, K. C. P.; SILVA, M. G.; QUEIROZ, H. A. Atributos físico-químicos de um Latossolo do Cerrado brasileiro e sua relação com características dendrométricas do eucalipto. Revista Brasileira de Ciência do Solo, v. 34, p. 163-173, 2010.

MACHADO, J. S.; STEINER, F.; ZOZ, F.; HONDA, G. B.; OLIVEIRA, B. L. N. Effects of aluminum on seeds germination and Initial growth of physic nut seedlings. Revista de Agricultura Neotropical, v. 2, n. 1, p. 24-31, 2015.

MERIÑO-GERGICHEVICH, C.; ALBERDI, M.; IVANOC, A. G.; REYES-DIAZ, M. Al ${ }^{3+}$ $\mathrm{Ca}^{2+}$ interaction in plants growing in acid soils: Al-phytotoxicity response to calcareous amendments. Journal of Soil Science and Plant Nutrition. V. 10, n. 3, p. 217-243, 2010.

MING, D. S.; GUNS, E.; EBERDING, A.; TOWERS, G. H. Isolation and characterization of compounds with anti-prostate cancer activity from Arctium lappa L. using bioactivity-guided fractionation. Pharmaceutical Biology, v. 42, n. 1, p. 44-48, 2004.

MORGAN, R. Enciclopédia das ervas e plantas medicinais. 9. ed. São Paulo: Hemus, 2003. $555 \mathrm{p}$.

MOTA, L. H. S.; SCALON, S. P. Q.; DRESCH, D. M.; SCALON, L. Q.; SILVA, C. J. Gas exchange and antioxidant activity accessions of Jatropha curcas L. under aluminium (Al) stress. Australian Journal of Crop Science, v. 14, n. 3, p. 510-516, 2020.

MUNARIN, E. E. O; ZÁRATE, N. A. H; VIEIRA, M. C; ROSA, Y. B. C. J; RODRIGUES, E. T. Espaçamentos entre plantas e cobertura do solo com cama-de-frango na produção da bardana (Arctium lappa L.). Revista Brasileira de Plantas Medicinais, v. 12, n. 2, p. 141148, 2010. 
RABEL, D. O.; MOTTA, A. C. V.; BARBOSA, J. Z.; MELO, V. F.; PRIOR, S. A. Depht distribution of exchangeable aluminum in acid soils: a study from subtropical Brazil. Acta Scientiarum. Agronomy, v. 40, p. 1-10, 2018.

SAMAD, R.; RASHID, P.; KARMOKER, J. L. Effects of aluminium toxicity on germination of seeds and its correlation with $\mathrm{K}^{+}, \mathrm{Cl}^{-}$and $\mathrm{Al}^{3+}$ accumulation in radicle and plumule of Oryza sativa L. and Cicer aeriatinum L. Bangladesh Journal of Botany, v. 46, n. 3, p. 979-986, 2017.

SCHEFFER-BASSO, S. M.; PRIOR, B. C. Aluminum toxicity in roots of legume seedlings assessed by topological analysis. Acta Scientiarum. Agronomy, v. 37, n. 1, p. 61-68, 2015.

SILVA, P.; MATOS, M. Assessment of the impact of aluminium on germination, early growth and free proline content in Lactuca sativa L. Ecotoxicology and Environmental Safety, v. 131, p. 151-156, 2016.

SIMONOVICOVÁ, M.; TAMAS, L.; HUTTOVÁ, J.; MISTRIK, I. Effect of aluminium on oxidative stress related enzymes activities in barley roots. Biologia Plantarum, v. 48, n. 2, p. $261-266,2004$.

SOUZA, M. C.; BUENO, P. C. P.; MORELLATO, L. P. C.; HABERMANN, G. Ecological strategies of $\mathrm{Al}$-accumulating and non-accumulating functional groups from the Cerrado sensu stricto. Anais da Academia Brasileira de Ciências, v. 87, n. 2, p. 813-823, 2015.

VENDRAME, P. R. S.; BRITO, O. R.; GUIMARÃES, M. F.; MARTINS, E. S.; BECQUER, T. Fertility and acidity status of Latossolos (oxisols) under pasture in the Brazilian Cerrado. Anais da Academia Brasileira de Ciências, v. 82, n. 4, p. 1085-1094, 2010.

WEBER, O. L. S.; CHITOLINA, J. C.; CAMARGO, O. A.; ALLEONI, L. R. F. Cargas elétricas estruturais e variáveis de solos tropicais altamente intemperizados. Revista Brasileira de Ciência do Solo, v. 29, p. 867-873, 2005.

YANG, J. L.; ZHU, X. F.; PENG, Y. X.; ZHENG, C.; LI, G. L.; LIU, Y.; SHI, Y. Z.; ZHENG, S. J. Cell wall hemicellulose contributes significantly to aluminum adsorption and root growth in Arabidopsis. Plant Physiology, v. 155, p. 1885-1892, 2011.

ZHANG, H.; TAN, Z. Q.; HU, L. Y.; WANG, S. H.; LUO, J. P.; JONES, R. L. Hydrogen sulfide alleviates aluminum toxicity in germinating wheat seedlings. Journal of Integrative Plant Biology, v. 52, n. 6, p. 556-567, 2010.

ZHENG, S. J.; LIN, X. Y.; YANG, J. L.; LIU, Q.; TANG, C. The kinetics of aluminum adsorption and desorption by root cell walls of an aluminum resistance wheat (Triticum aestivum L.) cultivar. Plant Soil, v. 261, p. 85-90, 2004. 


\section{ABSTRACT}

Aluminium (Al) in acid soils reduces the physiological potential of seeds and limits growth of several species of agronomic and medicinal interest. However, information on Al toxicity in Arctium lappa L. (burdock, Asteraceae) is scarce. The aimed of this study was to evaluate the effect of aluminium stress on germination and vigor of $A$. lappa seedlings. Five concentrations of hydrated aluminium sulfate $\mathrm{Al}_{2}\left(\mathrm{SO}_{4}\right)_{3} \cdot 16 \mathrm{H}_{2} \mathrm{O}: 0$ (control), $5,10,15$ and 20 mmol L-1 were tested. The germination test was performed in Gerbox boxes (on paper - SP) and in paper roll - RP, using germitest ${ }^{\circledR}$ paper wetted 2.5 times its dry wight. The seeds were kept in B.O.D. chambers, under 20-30 ${ }^{\circ} \mathrm{C}$ and constant withe light. Physiological potential of the seeds and vigor was evaluated by tests of first germination count ( $4^{\text {th }}$ day), germination $\left(7^{\text {th }}\right.$ day) and seedlings length. We observed a reduction in germination as $\mathrm{Al}$ concentration increased on the substrate SP. The lower aerial part length of the seedlings occurred with $20 \mathrm{mmol} \mathrm{L}^{-1} \mathrm{Al}$ and on the substrate SP. Occurred a root inhibition of seedlings as Al concentration increased in both substrates, especially on the SP. Aluminium stress and substrate SP negatively affected seeds germination and vigor of $A$. lappa seedlings.

Keywords: Burdock. Stress. Medicinal plant. Physiological potential.

\section{RESUMEN}

El aluminio (Al) presente en los solos ácidos reduce el potencial fisiológico de semillas y limita el crecimiento de plántulas de diversas especies de interés agronómico y medicinal. Entretanto, informaciones de toxicidad de Al en Arctium lappa L. (bardana, Asteraceae) son escasas. El objetivo de este estudio fue evaluar el efecto del estrés por aluminio en la germinación y en el vigor de plántulas de A. lappa. Foram investigando cinco concentraciones de sulfato de aluminio hidratado $\mathrm{Al}_{2}\left(\mathrm{SO}_{4}\right)_{3} \cdot 16 \mathrm{H}_{2} \mathrm{O}: 0$ (control), $5,10,15 \mathrm{e}$ $20 \mathrm{mmol} \mathrm{L}^{-1}$. El test de germinación fue hecho en cajas de tipo Gerbox (sobre papel - SP) y en rollo de papel - RP, utilizando papel germitest ${ }^{\circledR}$ humedecidos 2,5 veces su peso seco. Las semillas se mantuvieron en cámaras de B.EL.D, sobre $20-30^{\circ} \mathrm{C}$ y luz blanca constante. El potencial fisiológico de las semillas y el vigor de plántulas se evaluaron por medio de los testes de primer conteo de germinación (4 días), germinación (7 días) y largo de plántulas. Observamos reducción de la germinación conforme aumento de la concentración de Al en substrato SP. Las menores larguras de la parte aérea de las plántulas ocurrieron con 20 $\mathrm{mmol} \mathrm{L}^{-1}$ de Al y en el substrato SP. Ocurrió inhibición radicular de las plántulas conforme aumento de la concentración de Al en los dos substratos, especialmente en el SP. El estrés por aluminio y substrato SP afecto negativamente la germinación de semillas y el vigor de las plántulas de $A$. lappa.

Palabras-clave: Bardana. Estrés. Planta medicinal. Potencial fisiológico. 


\section{LICENÇA DE USO}

Este é um artigo publicado em acesso aberto (Open Access) sob a licença Creative Commons Atribuição 4.0 Internacional (CC BY 4.0), que permite uso, distribuição e reprodução em qualquer meio, desde que o trabalho original seja corretamente citado. Mais informações em: http://creativecommons.org/licenses/by/4.0

\section{CONFLITO DE INTERESSES}

Os autores declaram que não há conflito de interesses neste trabalho.

\section{CONTRIBUIÇÕES AUTORAIS}

Autor 1: responsável pela condução experimental, coleta de dados, interpretação e redação científica.

Autor 2: responsável pelo planejamento, análises estatísticas, redação e revisão do manuscrito.

Autor 3; 4 e 5: responsáveis pela condução experimental, coleta de dados, interpretação e redação científica.

Autor 6: responsável pela redação e revisão do manuscrito.

\section{FINANCIAMENTO}

Os autores agradecem ao Conselho Nacional de Desenvolvimento Científico e Tecnológico (CNPq) e Coordenação de Aperfeiçoamento de Pessoa de Nível Superior (CAPES), pela concessão de bolsas, e à Fundação de Apoio ao Desenvolvimento de Ensino, Ciência e Tecnologia do Mato Grosso do Sul (FUNDECT), pelo apoio financeiro.

\section{COMO REFERENCIAR}

SILVERIO, Juliana Milene; SANTOS, Cleberton Correia; BERNARDES, Rodrigo da Silva; ESPÍNDOLA, Rodrigo da Silva; MEURER, Hércules Lazari; VIEIRA, Maria do Carmo. GERMINAÇÃO DE SEMENTES E VIGOR DE PLÂNTULAS DE Arctium lappa L. SUBMETIDAS À TOXICIDADE DE ALUMÍNIO. Revista Brasileira de Engenharia de Biossistemas (Tupã), v. 15, e15007, jan./dez. 2021. Disponível em: https://seer.tupa.unesp.br/index.php/BIOENG/article/view/949. Acesso em: [dia] [mês abreviado]. [ano]. DOI: http://dx.doi.org/10.18011/bioeng2020v14n4p154$\underline{167}$

\section{RESPONSABILIBADE EDITORIAL}

Prof. Dr. Fernando Ferrari Putti ${ }^{1}$, Prof. Dr. Paulo Sérgio Barbosa dos Santos ${ }^{1}$, Prof. Dr. Eduardo Festozo Vicente ${ }^{1}$ e Prof. Dr. Diogo de Lucca Sartori ${ }^{1}$

${ }^{1}$ Universidade Estadual Paulista "Júlio de Mesquita Filho", FCE - Faculdade de Ciências e Engenharia, Tupã, SP, Brasil. 